\title{
Antioxidant, Hepatoprotective Potential and Chemical Profiling of Propolis Ethanolic Extract from Kashmir Himalaya Region Using UHPLC-DAD-QToF-MS
}

\author{
Adil F. Wali, ${ }^{1}$ Bharathi Avula, ${ }^{2}$ Zulfiqar Ali, ${ }^{2}$ Ikhlas A. Khan, ${ }^{2,3}$ Ahlam Mushtaq, \\ Muneeb U. Rehman, ${ }^{5}$ Seema Akbar, ${ }^{6}$ and Mubashir Hussain Masoodi ${ }^{1}$ \\ ${ }^{1}$ Department of Pharmaceutical Sciences, University of Kashmir, Srinagar, Jammu and Kashmir 190006, India \\ ${ }^{2}$ National Center for Natural Products Research, Research Institute of Pharmaceutical Sciences, The University of Mississippi, \\ University, MS 38677, USA \\ ${ }^{3}$ Division of Pharmacognosy, Department of BioMolecular Sciences, School of Pharmacy, The University of Mississippi, \\ University, MS 38677, USA \\ ${ }^{4}$ Department of Biochemistry, University of Kashmir, Srinagar, Jammu and Kashmir 190006, India \\ ${ }^{5}$ Department of Biochemistry, Faculty of Veterinary Sciences and Animal Husbandry, Sher-e-Kashmir University of \\ Agricultural Sciences and Technology of Kashmir, Jammu and Kashmir 190006, India \\ ${ }^{6}$ Central Council for Research in Unani Medicine, University of Kashmir, Srinagar, Jammu and Kashmir 190006, India
}

Correspondence should be addressed to Mubashir Hussain Masoodi; mubashir@kashmiruniversity.ac.in

Received 14 May 2015; Revised 15 July 2015; Accepted 16 July 2015

Academic Editor: Javier González Gallego

Copyright (C) 2015 Adil F. Wali et al. This is an open access article distributed under the Creative Commons Attribution License, which permits unrestricted use, distribution, and reproduction in any medium, provided the original work is properly cited.

\begin{abstract}
The aim of this study was to examine hepatoprotective effect of ethanolic extract of propolis (KPEt) from Kashmir Himalaya against isoniazid and rifampicin (INH-RIF) induced liver damage in rats. Hepatic cellular injury was initiated by administration of INHRIF combination $(100 \mathrm{mg} / \mathrm{kg})$ intraperitoneal (i.p.) injection for 14 days. We report the protective effects of KPEt against INHRIF induced liver oxidative stress, inflammation, and enzymatic and nonenzymatic antioxidants. Oral administration of KPEt at both doses (200 and $400 \mathrm{mg} / \mathrm{kg}$ body weight) distinctly restricted all modulating oxidative liver injury markers and resulted in the attenuation of INH-RIF arbitrated damage. The free radical scavenging activity of KPEt was evaluated by DPPH, nitric oxide, and superoxide radical scavenging assay. The components present in KPEt identified by ultra high performance liquid chromatography diode array detector time of flight-mass spectroscopy (UHPLC-DAD-QToF-MS) were found to be flavonoids and phenolic acids. The protective efficacy of KPEt is possibly because of free radical scavenging and antioxidant property resulting from the presence of flavonoids and phenolic acids.
\end{abstract}

\section{Introduction}

Tuberculosis (TB) is a foremost global health concern over years. According to World Health Organization (WHO) global tuberculosis reports, globally there are over 9 million people who develop TB each year and India has been classified on 8th rank among the 22 high burden countries [1]. Rifampicin (RIF) and isoniazid (INH) are the front line drugs that are used in the chemoprophylaxis and management of TB [2]. Previously published reports suggest that INH-RIF has potential of hepatic toxicity. Liver toxicity and hepatitis are presumed to be augmented with synergistic use of many medications including RIF and alcohol abuse. There is increased level of liver enzyme markers in serum (aspartate transaminase and alanine transaminase), fatal hepatitis, bilirubinemia, bilirubinuria, and jaundice, with dosing schedule consisting of INH and RIF. The common prevenient symptoms of hepatitis are anorexia, nausea, vomiting, fatigue, malaise, and weakness [3,4]. Sarich et al. reported that administration of INH-RIF dose simultaneously in rabbits results in elevation of phospholipids and a reduction in phosphatidylcholine, cardiolipin, and inorganic phosphates, 
possibly via a choline deficiency, which may lead to the observed liver toxicity [5]. Further Zhang et al. observed that coadministration INH-RIF caused steatosis, increased apoptosis of the hepatocytes, and hepatic oxidative stress [6]. About 9.5\% Indian patients have been reported to develop hepatotoxicity due to antitubercular therapy [7]. Therefore, there is requirement to investigate the natural molecules that can successfully diminish the toxicity to improve their chemotherapeutic efficacy. Nowadays, dietary supplements containing natural products, fruits, vegetables, medicinal plants, and herbs have many biological properties and have potential to fight against several human pathogens [8].

Propolis, also known as "bee glue," is a resinous material produced by honeybees which they collect from different species of plants, to use it as beehive sealant. The chemical magnitudes of the propolis are influenced by various aspects such as geographical site, seasonal diversification, flora origin, and collection time (year), which is responsible for the diverse pharmacological activities of the propolis [9]. In the past, propolis has been used in folk remedy for several ailments and various pharmacological properties such as antiinflammatory [10], antimicrobial [11], antioxidant [12], immunostimulant [13], antitumor [14], neuroprotective [15], and hepatoprotective activity [16] have been reported.

Our present study is the first approach to investigate and validate scientifically in vitro antioxidant potential followed by chemical profiling using UHPLC-DAD-QToF-MS and in vivo hepatoprotective activity of ethanolic extract of propolis from Kashmir Himalaya region.

\section{Materials and Methods}

2.1. Material Collection and Preparations of Propolis Ethanolic Extract (KPEt). The propolis used for study was collected from Central Kashmir, Rangil, Ganderbal (Jammu and Kashmir, India), which was identified and authenticated from "Research and Training Center for Pollinator, Pollinizer and Pollination Management," Sher-e-Kashmir University of Agricultural Sciences and Technology, Kashmir, India, under specimen voucher number AU/DR/NAE-II/137. The propolis was packed into percolator and extracted with $100 \%$ ethanol at room temperature with constant agitation for $24 \mathrm{hrs}$. After several cycles of extraction the extract was filtered and recovered under reduced pressure. The yield of KPEt was $33.37 \% \mathrm{w} / \mathrm{w}$. The extract was then kept in desiccator to remove moisture and finally kept in refrigerator for further use.

2.2. Chemical Profiling of KPEt Using UHPLC-DAD-QToF$M S$. Chemical profiling of KPEt was carried out on LC-MS instrument (Agilent QToF-MS 6530 series, Agilent Technologies, Palo Alto, CA, USA) coupled with Agilent UHPLC 1290 Series (Agilent Technologies, Palo Alto, CA, USA) with ESI interface. The LC-MS operating parameters were as follows: the spectra were obtained in ESI+ and ESI- modes, gas temperature $250^{\circ} \mathrm{C}$, gas flow $10 \mathrm{~L} / \mathrm{min}$, nebulizer $30 \mathrm{psig}$, sheath gas temperature $325^{\circ} \mathrm{C}$, capillary voltage $3.0 \mathrm{kV}$, and fragmentor $125 \mathrm{~V}$. The chromatographic separation was achieved on ZORBAX SB-C18 RRHD $1.8 \mu$ column $(2.1 \times 150 \mathrm{~mm})$ at a flow rate of $0.25 \mathrm{~mL} / \mathrm{min}$ with mobile phase (A) water and (B) acetonitrile, both containing $0.1 \%$ formic acid with gradient program as follows: A $85 \%: 15 \%$ B to A $45 \%: \mathrm{B}$ $55 \%$ in $20 \mathrm{~min}$ and to $100 \% \mathrm{~B}$ in next $3 \mathrm{~min}$. The column temperature was operated at $40^{\circ} \mathrm{C}$ and injection volume $2 \mu \mathrm{L}$. DAD spectra were acquired over a scan range of 190-600 nm. All the operations, acquisition, and analysis of data were controlled by Agilent MassHunter Acquisition Software version A.05.00 and processed with MassHunter Qualitative Analysis Software version B.05.00. Each sample was analyzed in both positive and negative modes in the range of $\mathrm{m} / z=$ 100-1000. Accurate mass measurements were obtained by means of ion correction techniques using reference masses at $m / z 121.0509$ (protonated purine) and 922.0098 [protonated hexakis $(1 \mathrm{H}, 1 \mathrm{H}, 3 \mathrm{H}$-tetrafluoropropoxy) phosphazine or $\mathrm{HP}$ 921] in positive ion mode, while at $\mathrm{m} / z 112.9856$ (deprotonated trifluoroacetic acid (TFA)) and 1033.9881 (TFA adducted HP-921) they were used in negative ion mode. The compounds were confirmed in each spectrum. For this purpose, the reference solution was introduced into the ESI source via a T-junction using an Agilent Series 1200 Isocratic Pump (Agilent Technologies, Santa Clara, CA, USA) using a $100: 1$ splitter set at a flow rate of $20 \mu \mathrm{L} / \mathrm{min}$.

\subsection{Antioxidant Property}

2.3.1. 1,1-Diphenyl-2-picrylhydrazyl Radical Scavenging Activity $(D P P H)$. The free radical scavenging assay of KPEt was measured using a modified DPPH assay method by Huang et al. [20]. Aliquots of $0.3 \mathrm{~mL}$ of various concentrations $(50-250 \mu \mathrm{g} / \mathrm{mL})$ of $K P E t$ were mixed with a solution of $0.2 \mathrm{mmol} / \mathrm{L} \mathrm{DPPH}$ in methanol $(2.7 \mathrm{~mL})$. The mixture was mixed vigorously, and absorbance value was recorded at $517 \mathrm{~nm}$ using UV-Spectrophotometer (Model UVD-2950, Labomed Inc.) after incubation at room temperature for $15 \mathrm{~min}$ in dark. The percentage of radical scavenging activity is determined using the following formula:

$$
\text { Radical scavenging activity } \%=\left[\frac{A_{\mathrm{C}}-A_{\mathrm{S}}}{A_{\mathrm{C}}} * 100\right] \text {, }
$$

where $A_{\mathrm{C}}$ is the absorbance of DPPH without sample and $A_{\mathrm{S}}$ is the absorbance of the DPPH with KPEt/vitamin C. All the samples were investigated in triplicate.

2.3.2. Nitric Oxide Radical Scavenging Assay. Nitric oxide radical inhibition was estimated using Griess Ilosvay reaction [21]. In this investigation, Griess Ilosvay reagent was generally modified by using naphthyl ethylenediamine dihydrochloride $(0.1 \% \mathrm{w} / \mathrm{v})$ instead of 1-naphthylamine $(5 \%)$. The reaction mixture $(3 \mathrm{~mL})$ containing $2 \mathrm{~mL}$ of $10 \mathrm{mM}$ sodium nitroprus-

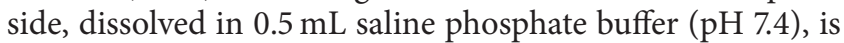
mixed with $0.5 \mathrm{~mL}$ of KPEt at various concentrations (50$250 \mu \mathrm{g} / \mathrm{mL}$ ) and was incubated at $25^{\circ} \mathrm{C}$ for 150 minutes. After incubation, $0.5 \mathrm{~mL}$ of the incubated aliquots is withdrawn and mixed with $0.5 \mathrm{~mL}$ of Griess reagent [1.0 mL sulfanilic acid reagent, $0.33 \%$ in $20 \%$ glacial acetic acid] at room temperature for $5 \mathrm{~min}$ with $1 \mathrm{~mL}$ of naphthyl ethylenediamine dichloride $(0.1 \% \mathrm{w} / \mathrm{v})$. The mixture is then incubated at room 
temperature for $30 \mathrm{~min}$ and its absorbance value was recorded at $546 \mathrm{~nm}$ using UV-Spectrophotometer (Model UVD-2950, Labomed Inc.).

The percentage of nitric oxide scavenging activity is determined using the following formula:

Nitric Oxide Scavenging Activity \%

$$
=\left[\frac{A_{\mathrm{C}}-A_{\mathrm{S}}}{A_{\mathrm{C}}} * 100\right] \text {, }
$$

where $A_{\mathrm{C}}$ is the absorbance of mixture of Griess reagent and naphthyl ethylenediamine dihydrochloride and $A_{\mathrm{S}}$ is the absorbance of mixture of Griess reagent and naphthyl ethylenediamine dihydrochloride solution with KPEt/chrysin. All the samples were investigated in triplicate.

2.3.3. Superoxide Radical Anion Scavenging Assay. The superoxide anion radical scavenging activity was investigated by riboflavin-light-NBT system [22]. In this assay the reaction

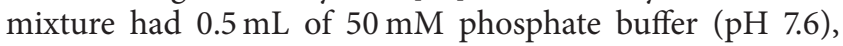
$0.3 \mathrm{~mL}$ riboflavin $(50 \mathrm{mM}), 0.25 \mathrm{~mL}$ phenazine methosulphate $(20 \mathrm{mM})$, and $0.1 \mathrm{~mL}$ nitro blue tetrazolium $(0.5 \mathrm{mM})$, before $1 \mathrm{~mL}$ KPEt solution was added at various concentrations $(50-250 \mu \mathrm{g} / \mathrm{mL})$. Reaction commenced as the reaction mixture was illuminated with different concentrations of the KPEt using a fluorescent lamp. After $20 \mathrm{~min}$ of incubation, the absorbance values were recorded at $560 \mathrm{~nm}$ using UVSpectrophotometer (Model UVD-2950, Labomed Inc.). The percentage of superoxide scavenging activity was calculated as follows:

Superoxide scavenging capability \%

$$
=\left[\frac{A_{\mathrm{C}}-A_{\mathrm{S}}}{A_{\mathrm{C}}} * 100\right] \text {, }
$$

where $A_{\mathrm{C}}$ is the absorbance of the reaction mixture without $K P E t /$ quercetin and $A_{\mathrm{S}}$ is the absorbance of the reaction mixture with $K P E t / q u e r c e t i n$. All the samples were investigated in triplicate.

\subsection{Evaluation of Hepatoprotective Activity}

2.4.1. Experimental Animals. Male Wistar albino rats (8-10 weeks old) were selected and used in the present experiment. The animals were housed in a group of six in polypropylene cages with saw dust as bedding in animal house facility of Department of Pharmaceutical Sciences, University of Kashmir. All the experiments were performed according to protocols authorized by CPCSEA animal ethical committee; the animal studies had approval of IAEC, Department of Pharmaceutical Sciences, University of Kashmir, under project number F-IAEC (Pharm. Sc.) APPROVAL/2013/21, dated September 28th, 2013. The animals were maintained under exposure to a $12 \mathrm{~h} / 12 \mathrm{~h} \mathrm{light/dark} \mathrm{cycle} \mathrm{at} \mathrm{a} \mathrm{room} \mathrm{tem-}$ perature of $22-24^{\circ} \mathrm{C}$ and free access to standard laboratory feed (M/s Ashirwad Industries, Mohali, India) and water ad libitum.
2.4.2. Acute Toxicity Testing. The acute toxicity study was performed as per Organization for Economic Cooperation and Development [23]. Single dose of KPEt $2000 \mathrm{mg} / \mathrm{Kg}$ b.wt was orally administrated. Mortality, behavior activities, body weight, and food and water consumption were monitored for 14 days.

2.4.3. Animal Study Design. The treatment execution for KPEt of propolis and the approach of verifying its hepatoprotective efficacy against hepatotoxins was based on the prelude dose dependent pilot study. All rats were divided into five groups of six rats each. Selection of the dose course was based on acute toxicity study. The following treatment regimen was followed for 14 days study [24]:

(i) Group I: only normal saline, $0.9 \%$ p.o.

(ii) Group II: INH-RIF $100 \mathrm{mg} / \mathrm{kg}$ b.wt i.p.

(iii) Group III: INH-RIF $100 \mathrm{mg} / \mathrm{kg}$ b.wt i.p. + Silymarin $100 \mathrm{mg} / \mathrm{kg}$ b.wt p.o.

(iv) Group IV: INH-RIF $100 \mathrm{mg} / \mathrm{kg}$ b.wt i.p. $+K P E t$ $200 \mathrm{mg} / \mathrm{kg}$ b.wt p.o.

(v) Group V: INH-RIF $100 \mathrm{mg} / \mathrm{kg}$ b.wt i.p. + KPEt $400 \mathrm{mg} / \mathrm{kg}$ b.wt p.o.

At the end of the study, rats were sacrificed by cervical dislocation under mild anesthesia and blood was taken by dorsal vena cava for various serological parameters. Liver was dissected out and used for in vivo antioxidant studies, histological and immunohistochemistry examination.

2.4.4. Estimation of Serum Biochemistry. The hepatoprotective potential of KPEt was studied by assessing the levels of sera ALT, AST, ALP, TP, T. bil, CHL, and TG using assay kit (Accurex Biomedical kits, Mumbai, India) according to the manufacturer's protocol on RIELE photometer $5010 \mathrm{~V} 5+$ semi-auto-analyzer (Berlin, Germany).

2.4.5. Determination of In Vivo Antioxidant Enzyme Activities. The liver tissues were homogenized and were used for various in vivo antioxidant enzyme assays such as GPx, MDA, XO, SOD, and CAT [25].

2.4.6. Histological Examination. The wet livers tissues were fixed in formalin and dehydrated; a section of liver $5 \mu \mathrm{m}$ was cut and stained with haematoxylin and eosin (H\&E) dye for examination. Then these slides were investigated for histopathological alteration under fluorescent microscope BX-100 (Olympus Life Science, Europa GMBH, Wendenstrasse 14-18, 20097 Hamburg, Germany).

2.4.7. Immunohistochemistry Examination. The liver tissues were fixed in formalin and embedded in paraffin. Sections of $5 \mathrm{~mm}$ thickness were cut onto polylysine coated glass slides. Sections were deparaffinized three times $(5 \mathrm{~min})$ in xylene followed by dehydration in graded ethanol and finally rehydrated in running tap water. For antigen retrieval, sections were boiled in $10 \mathrm{mM}$ citrate buffer $(\mathrm{pH}$ 6.0) for 5-7 min. 

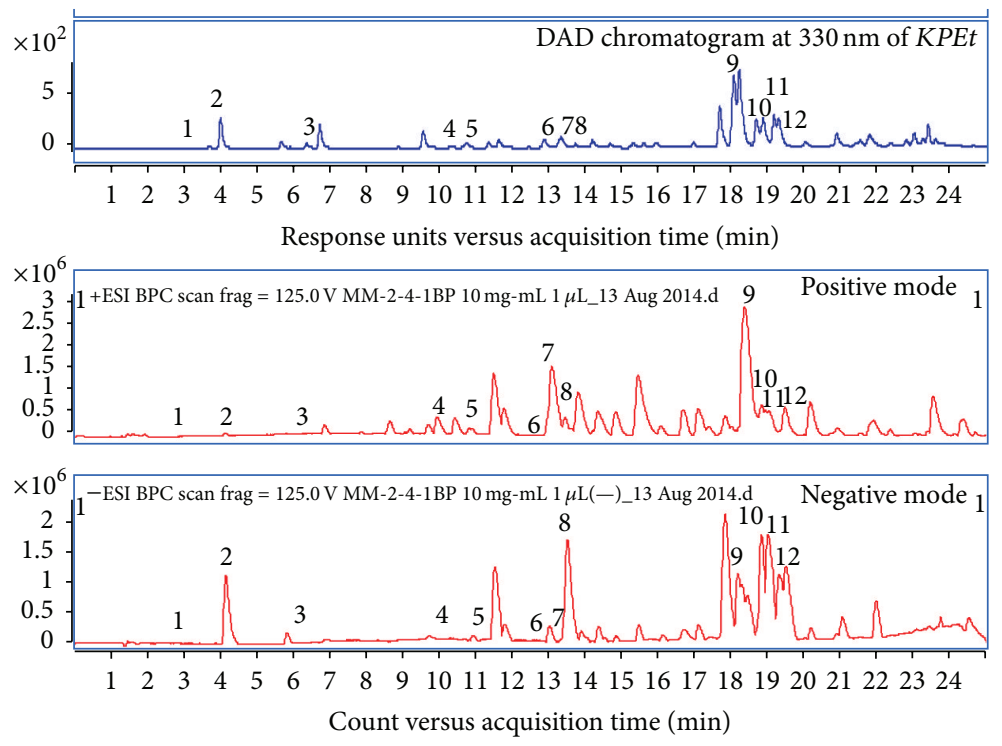

FIGURE 1: Representative chromatographic profile of KPEt at $330 \mathrm{~nm}$ and BPC in both positive and negative mode.

Sections were incubated with hydrogen peroxide for $15 \mathrm{~min}$ to minimize nonspecific staining and then rinsed three times (5 min each) with $1 x$ PBST (0.05\% Tween 20). Blocking solution was applied for $10 \mathrm{~min}$; then sections were incubated with diluted (1:100 for NF- $\kappa$ B and COX-2) primary antibodies, purified rabbit polyclonal anti-NF- $\kappa \mathrm{B}$ antibody (BioLegend), and rabbit polyclonal anti-COX-2 antibody (BioVision), overnight at $4^{\circ} \mathrm{C}$ in humid chamber. Further processing was done according to the instructions of UltraVision plus Detection System Anti-Polyvalent, HRP/DAB (Ready-ToUse) staining kit (Thermo Scientific system). The peroxidase complex was visualized with 3,30-diaminobenzidine (DAB). Lastly the slides were counterstained with hematoxylin, cleaned in xylene, and dehydrated with ethanol and after DPX mounting microscopic (BX51 Olympus) analysis was done at 400x magnification [26].

2.4.8. Quantitative Evaluation of $N F-\kappa B$ and COX-2 Immunostaining. According to the diffuseness of the DAB staining, sections were graded as 0 (no staining), 1 (staining, 25\%), 2 (staining between $25 \%$ and 50\%), 3 (staining between $50 \%$ and $75 \%$ ), or 4 (staining $>75 \%$ ). According to staining intensity, sections were graded as follows: 0 (no staining), 1 (weak but detectable staining), 2 (distinct staining), or 3 (intense staining). Immunohistochemical staining scores were obtained by adding the diffuseness and intensity scores. All slides were examined by two independent observers who were unaware of the experimental protocol. The slides with discrepant evaluations were reevaluated, and a consensus was reached. Measurements were carried out using an Olympus BX51 microscope using objectives with 40x magnifications.

2.5. Statistical Analysis. All the results were expressed as mean \pm S.E.M. Difference between the groups was analyzed by using one-way analysis of variance (ANOVA) followed by the Tukey-Kramer multiple comparison test using GraphPad prism software version 6.01 (GraphPad software, San Diego, USA).

\section{Results and Discussion}

This work is proposed to investigate the antioxidant potential and hepatoprotective efficiency of ethanolic extract of the propolis from Kashmir region along with its chemical profiling using UHPLC-DAD-QToF-MS. Propolis contains various bioactive secondary metabolites mostly phenolic acids followed by flavonoids, which have been identified as potent antioxidants [27]. An investigation of KPEt was carried out by means of UHPLC-DAD-QToF-MS; the accurate mass and $\lambda_{\max }$ of the identified compounds were correlated with reference library, reference samples spectra, research papers, and online mass spectral based catalog like https:/origin-scifinder.cas.org/scifinder/login and http://www.ncbi.nlm.nih.gov/pmc/. The compounds identified are hydroxycinnamic acid derivatives and flavonoids (flavones, flavonol, and flavanone derivatives) and the order of elution in both base peak chromatograms (BPC) positive and negative mode is shown in Figure 1; all the compounds have to be detected in both positive and negative modes. In (-)-ESI-MS, the mass spectra of the chromatographic peaks showed deprotonated molecules $[\mathrm{M}-\mathrm{H}]^{-}$and protonated molecules $[\mathrm{M}+\mathrm{H}]^{+}$in positive ion mode. The data provided in Table 1 is supported by the information acquired from the analyses represented in the TIC and UV chromatogram in Figure 1.

From the previous investigation it has been reported that presence of flavonoids and phenolic acids is responsible for hepatoprotective activity by decreasing the level of hepatic markers, lipid peroxidation, and attenuates free radical scavenging potential [28-30]. Flavonoids, particularly flavonols, possess various pharmacological activities that contribute to health benefits that include antioxidant and hepatoprotective 
TABLE 1: Characterization of chemical constituents of KPEt using UHPLC-DAD-QToF-MS.

\begin{tabular}{|c|c|c|c|c|c|c|c|}
\hline $\begin{array}{l}\text { Peak } \\
\text { number }\end{array}$ & $R_{t}(\min )$ & Exact mass & $\begin{array}{c}\lambda_{\max } \text { observed } \\
(\mathrm{nm})\end{array}$ & $\begin{array}{l}\text { Mass observed } \\
{[\mathrm{M}+\mathrm{H}]^{+}(\mathrm{m} / \mathrm{z})}\end{array}$ & $\begin{array}{l}\text { Mass observed } \\
{[\mathrm{M}-\mathrm{H}]^{-}(m / z)}\end{array}$ & Molecular formula & Compound name \\
\hline 1 & 3.14 & 354.0945 & 295 sh, 325 & $355.1021(355.1024)$ & $353.0874(353.0878)$ & $\mathrm{C}_{16} \mathrm{H}_{18} \mathrm{O}_{9}$ & ${\text { Chlorogenic } \text { acid }^{1,3}}^{1,3}$ \\
\hline 2 & 4.18 & 180.0417 & 324,298 & $181.0495(181.0495)$ & $179.0351(179.0350)$ & $\mathrm{C}_{9} \mathrm{H}_{8} \mathrm{O}_{4}$ & Caffeic acid ${ }^{1,2,3}$ \\
\hline 3 & 6.55 & 194.0574 & 324,298 & $195.0654(195.0652)$ & $193.0506(193.0506)$ & $\mathrm{C}_{10} \mathrm{H}_{10} \mathrm{O}_{4}$ & Ferulic acid ${ }^{1,2,3}$ \\
\hline 4 & 10.85 & 286.0472 & 277 & $287.0552(287.0550)$ & $285.0403(285.0405)$ & $\mathrm{C}_{15} \mathrm{H}_{10} \mathrm{O}_{6}$ & Luteolin $^{1,2,3}$ \\
\hline 5 & 10.99 & 302.0421 & 256,372 & $303.0496(303.0499)$ & $301.0354(301.0354)$ & $\mathrm{C}_{15} \mathrm{H}_{10} \mathrm{O}_{7}$ & Quercetin $^{2,3}$ \\
\hline 6 & 12.93 & 272.0679 & 289,252 & $273.0759(273.0757)$ & $271.0615(271.0612)$ & $\mathrm{C}_{15} \mathrm{H}_{12} \mathrm{O}_{5}$ & Naringenin $^{3}$ \\
\hline 7 & 13.06 & 270.0523 & 267,338 & $271.0606(271.0601)$ & $269.0454(269.0455)$ & $\mathrm{C}_{15} \mathrm{H}_{10} \mathrm{O}_{5}$ & Apigenin $^{2,3}$ \\
\hline 8 & 13.40 & 286.0472 & 266,366 & $287.0554(287.0550)$ & $285.0404(285.0405)$ & $\mathrm{C}_{15} \mathrm{H}_{10} \mathrm{O}_{6}$ & Kaempferol $^{2,3}$ \\
\hline 9 & 18.41 & 254.0574 & $268,314 \mathrm{sh}$ & $255.0658(255.0652)$ & $253.0507(253.0506)$ & $\mathrm{C}_{15} \mathrm{H}_{10} \mathrm{O}_{4}$ & Chrysin $^{2,3}$ \\
\hline 10 & 18.83 & 256.073 & $290,330 \mathrm{sh}$ & $257.0811(257.0808)$ & $255.0662(255.0663)$ & $\mathrm{C}_{15} \mathrm{H}_{12} \mathrm{O}_{4}$ & Pinocembrin ${ }^{2,3}$ \\
\hline 11 & 18.99 & 270.0523 & $265,300 \mathrm{sh}, 358$ & $271.0605(271.0601)$ & $269.0461(269.0455)$ & $\mathrm{C}_{15} \mathrm{H}_{10} \mathrm{O}_{5}$ & Galangin $^{2,3}$ \\
\hline 12 & 19.51 & 314.0785 & $294,332 \mathrm{sh}$ & $315.0864(315.0863)$ & $313.0719(313.0718)$ & $\mathrm{C}_{17} \mathrm{H}_{14} \mathrm{O}_{6}$ & Pinobanksin acetate $e^{2,3}$ \\
\hline
\end{tabular}

$R_{t}$ : retention time.

${ }^{1}$ Confirmed with reference; ${ }^{2}$ confirmed with fragmentation pattern; ${ }^{3}$ confirmed with [17-19].

TABLE 2: $\mathrm{IC}_{50}$ (half maximal inhibitory concentration) in vitro antioxidant values of propolis from Kashmir Himalaya.

\begin{tabular}{|c|c|c|c|c|c|}
\hline & $\mathrm{IC}_{50}(\mu \mathrm{g} / \mathrm{mL})$ & $R^{2}$ & Reference & $\mathrm{IC}_{50}(\mu \mathrm{g} / \mathrm{mL})$ & $R^{2}$ \\
\hline DPPH scavenging & $52.16 \pm 6.39$ & 0.985 & Vitamin C & $11.28 \pm 5.23$ & 0.998 \\
\hline $\mathrm{NO}^{\bullet}$ scavenging & $74.62 \pm 5.23$ & 0.973 & Chrysin & $51.02 \pm 3.63$ & 0.989 \\
\hline $\mathrm{O}_{2}{ }^{--}$scavenging & $34.77 \pm 4.23$ & 0.991 & Quercetin & $42.54 \pm 5.10$ & 0.997 \\
\hline
\end{tabular}

Each value was presented as the mean \pm S.E.M; $n=3$.

activity [31]. Besides that flavonols also avert oxidative stress by direct scavenging of free radicals, metal chelation, and induction of antioxidant enzymes as well as phase II detoxifying enzymes [32].

DPPH assay is the most common assay used to determine the radical scavenging capacity of various compounds as it has ability to donate hydrogen to free radicals. The antioxidant property of KPEt was assessed by its potential to scavenge DPPH radical. The result in Table 2 depicted significant scavenging potential of KPEt with $\mathrm{IC}_{50}$ value of $52.16 \pm$ $6.39 \mu \mathrm{g} / \mathrm{mL}$ and the reference vitamin $\mathrm{C}$ showed scavenging potential of $11.28 \pm 5.23 \mu \mathrm{g} / \mathrm{mL}$. The mechanism behind the radical scavenging property is because of presence of flavonoids and phenolics, which are mostly weak acids in nature, and therefore act as proficient electron donors able to react with $\mathrm{O}_{2}{ }^{--}$depending upon the substitution in the phenolic ring [33].

Superoxide radical anion scavenging assay of KPEt showed $\mathrm{IC}_{50}$ value of $34.77 \pm 4.23 \mu \mathrm{g} / \mathrm{mL}$ while chrysin (reference) showed $\mathrm{IC}_{50}$ value of $42.54 \pm 5.10 \mu \mathrm{g} / \mathrm{mL}$. Superoxide radical anion $\left(\mathrm{O}_{2}{ }^{--}\right)$is generated by number of metabolic processes and has ability to react with the cell and induce cellular damage and various diseases [34]. Antioxidant capacity of various flavonoids is primarily due to scavenging of superoxide anion [35]. As shown in Table 2, $\mathrm{IC}_{50}$ value of KPEt is less than that of the reference; therefore, the results revealed that KPEt is having stronger scavenging ability than the reference.
Nitric oxide assay of KPEt demonstrated moderate antioxidant potential in nitric oxide scavenging assay with $\mathrm{IC}_{50}$ value of $74.62 \pm 5.23 \mu \mathrm{g} / \mathrm{mL}$, whereas the standard antioxidant quercetin (reference) showed $\mathrm{IC}_{50}$ value of $51.02 \pm$ $3.63 \mu \mathrm{g} / \mathrm{mL}$. Nitric oxide radical $\left(\mathrm{NO}^{\circ}\right)$ is essential in the regulation of various physiological and pathophysiological processes and is produced by specific nitric oxide synthases [36]. Nitric oxide radical reacts with superoxide radical anion $\left(\mathrm{O}_{2}{ }^{--}\right)$and produces peroxynitrite anion $\left(\mathrm{ONOO}^{-}\right)$[33] which in physiological environment forms adduct with $\mathrm{CO}_{2}$ dissolved in the body fluids; this adduct is believed to be responsible for the oxidative damage [37]. The results in Table 2 suggest that the KPEt has less effective nitric oxide scavenging potential than the reference.

During acute toxicity testing of KPEt no adverse/toxic signs were observed showing nontoxic nature of KPEt. On the basis of the results of acute toxicity testing $1 / 10$ th $(200 \mathrm{mg} / \mathrm{Kg}$ b.wt) and $1 / 5$ th $(400 \mathrm{mg} / \mathrm{Kg}$ b.wt) dose were selected to be administered in rats throughout the experiment.

Silymarin is a natural compound isolated from Silybum marianum, which is commonly known as milk thistle. Silymarin is a flavonolignan extract, mainly containing flavonoid, including silibinin or silibinin, silydianin, and silychristin [38]. Silymarin has been found cure numerous liver disorders as it has traditionally restored the efficacy of liver function and regeneration of hepatic cells [39]. Moreover, it is used as a reference drug and showed evidence of potent liver protective activity within the dose range of 25 to $200 \mathrm{mg} / \mathrm{kg}$ [40]. It has already been established that in RIF and INH 
TABLE 3: Effect of different doses of propolis on serum parameters in INH-RIF induced hepatotoxicity.

\begin{tabular}{lccccccc}
\hline & AST (IU/L) & ALT (IU/L) & ALP (IU/L) & T.bil (mg/dL) & TP (gm/dL) & CHL (gm/dL) & TG (gm/dL) \\
\hline Group I & $145.9 \pm 3.391$ & $166.5 \pm 2.939$ & $339.9 \pm 3.304$ & $0.845 \pm 0.385$ & $8.260 \pm 0.449$ & $70.75 \pm 3.154$ & $57.98 \pm 2.297$ \\
Group II & $303.4 \pm 3.654^{\ddagger}$ & $359.7 \pm 3.269^{\ddagger}$ & $515.3 \pm 2.191^{\ddagger}$ & $2.017 \pm 0.497^{\ddagger}$ & $4.713 \pm 0.169^{\ddagger}$ & $271.4 \pm 4.335^{\ddagger}$ & $165.3 \pm 3.036^{¥}$ \\
Group III & $176.9 \pm 3.588^{\#}$ & $205.6 \pm 2.802^{\#}$ & $379.6 \pm 3.747^{\#}$ & $1.103 \pm 0.049^{\#}$ & $6.468 \pm 0.177^{\#}$ & $107.1 \pm 3.037^{\#}$ & $93.31 \pm 2.400^{\#}$ \\
Group IV & $234.2 \pm 3.346^{\#}$ & $271.7 \pm 3.036^{\#}$ & $445.4 \pm 3.739^{\#}$ & $1.690 \pm 0.025^{\#}$ & $6.125 \pm 0.212^{\$}$ & $195.0 \pm 3.519^{\#}$ & $151.8 \pm 3.434^{*}$ \\
Group V & $290.1 \pm 2.959^{*}$ & $341.2 \pm 2.737^{\$}$ & $498.0 \pm 3.523^{\$}$ & $1.830 \pm 0.043^{*}$ & $4.263 \pm 0.870^{\text {ns }}$ & $256.0 \pm 3.587^{*}$ & $158.4 \pm 2.860^{\text {ns }}$ \\
\hline
\end{tabular}

Values are mean \pm S.E.M; $n=6 ;{ }^{¥} P<0.001$, toxic versus normal, ${ }^{*} P<0.05$, extract treated groups versus toxic, ${ }^{\$} P<0.01$, extract treated groups versus toxic, and $^{\#} P<0.001$, extract treated groups versus toxic; ns, not significant.

TABLE 4: Effect of different doses of propolis on in vivo antioxidant enzymes in INH-RIF induced hepatotoxicity.

\begin{tabular}{|c|c|c|c|c|c|}
\hline & $\begin{array}{c}\text { GPx } \\
\text { (nmol NADPH } \\
\text { oxidized/min/mg protein) }\end{array}$ & $\begin{array}{c}\text { XO } \\
\text { (mg of uric acid } \\
\text { formed/min/mg protein })\end{array}$ & $\begin{array}{c}\text { SOD } \\
\text { (units/mg protein) }\end{array}$ & $\begin{array}{c}\text { CAT } \\
\left(\mathrm{nmol} \mathrm{H} \mathrm{O}_{2}\right. \\
\text { consumed/min/mg protein) }\end{array}$ & $\begin{array}{c}\text { MDA } \\
\text { (nmol of MDA } \\
\text { formed/g tissue) }\end{array}$ \\
\hline Group I & $189.2 \pm 3.877$ & $2.072 \pm 0.642$ & $11.56 \pm 0.422$ & $4.707 \pm 0.345$ & $9.730 \pm 0.567$ \\
\hline Group II & $90.04 \pm 2.742^{¥}$ & $0.978 \pm 0.586^{¥}$ & $7.237 \pm 0.323^{¥}$ & $1.390 \pm 0.338^{¥}$ & $21.31 \pm 0.931^{¥}$ \\
\hline Group III & $128.2 \pm 2.710^{¥}$ & $1.743 \pm 0.780^{¥}$ & $9.012 \pm 0.323^{\$}$ & $2.718 \pm 0.333^{\#}$ & $15.62 \pm 0.512^{¥}$ \\
\hline Group IV & $109.1 \pm 2.247^{\#}$ & $1.892 \pm 0.894^{\$}$ & $8.098 \pm 0.291^{\mathrm{ns}}$ & $2.663 \pm 0.109^{\#}$ & $17.95 \pm 0.484^{*}$ \\
\hline Group V & $102.6 \pm 1.562^{*}$ & $1.842 \pm 0.507^{\#}$ & $8.833 \pm 0.211^{*}$ & $2.260 \pm 0.120^{*}$ & $16.80 \pm 0.948^{\$}$ \\
\hline
\end{tabular}

Values are mean \pm S.E.M; $n=6 ;{ }^{¥} P<0.001$, toxic versus normal, ${ }^{*} P<0.05$, extract treated groups versus toxic, ${ }^{\$} P<0.01$, extract treated groups versus toxic, and $^{\#} P<0.001$, extract treated groups versus toxic; ns, not significant.

induced toxicity there is change in liver cellular fortification mechanisms, both enzymatic and nonenzymatic [41]. During the acetylation of INH by the liver enzyme $\mathrm{N}$ acetyl transferase 2, acetylhydrazine and isonicotinic acid are produced. Further acetylhydrazine on hydrolysis produces hydrazine and diacetylhydrazine; both of these metabolites cause irremediable cellular injury [42]. RIF gets metabolized to desacetyl rifampicin in liver which on further hydrolysis forms 3-formyl rifampicin which is responsible for hepatocellular injury [43]. RIF is also a strong inducer of Cyt $\mathrm{P}_{450}$ when coadministrated with other antituberculosis drugs which lead to toxicity of liver [44]. The rodents were stressed with hepatoxin (INH-RIF) which induced hepatotoxicity and caused hepatic cellular injury which is comprised of centrilobular necrosis, hepatic cell augmentation, steatosis, and inhibition of endogenous antioxidants [45]. These in turn lead to the elevation of enzymes in serum due to the leakage of enzymes from liver (ALT, AST, ALP, and T.bil), increase in lipid profile (CHL, TG), and decrease in TP in blood. These liver enzymes in serum are constructive quantitative markers and nature of hepatic cell damage. Table 3 signifies the effects of INH-RIF and KPEt (200 mg and $400 \mathrm{mg} / \mathrm{Kg}$ b.wt) on enzymatic markers. In group II there was considerable elevation in the levels of hepatic enzymes, lipid profile, and lowering in total protein content as compared to group I $(P<0.001)$. In groups III, IV, and V after the administration of KPEt and INH-RIF there were significant decrease in ALT, AST, ALP, T.bil, CHL, and TG content and elevation in TP when compared with group II $(P<0.001$ and 0.01 , resp.). Therefore, treatment regimen executed with groups III and $\mathrm{V}$ demonstrated remarkable hepatoprotective activity by bringing the enzyme levels and other biochemical parameters towards normal as compared with group II.
The in vivo antioxidant ability of KPEt was investigated using INH-RIF stressed hepatotoxicity and the results revealed that in group II there were significant $(P<0.001)$ decrease in the concentration of GPx, CAT, SOD, and XO and increase in MDA level when compared with group I (Table 4). Raised levels of free radicals and oxidative stress are related to the hepatopathy due to augmentation of free radicals and slackening of scavenging capacity of the hepatocytes [46]. After the treatment with KPEt, there was noticeable decrease in the levels of MDA in groups III, IV, and V when compared with group II $(P<0.001$ and 0.01$)$. KPEt at the dose of $400 \mathrm{mg} / \mathrm{kg}$ b.wt group $\mathrm{V}$ substantially decreased the lipid peroxidation as compared with $200 \mathrm{mg} / \mathrm{kg}$ b.wt dose group IV. In groups III, IV, and V the levels of GPX, CAT, SOD, and $\mathrm{XO}$ were considerably increased after the administration of KPEt at the dose of $400 \mathrm{mg} / \mathrm{Kg}$ b.wt and $200 \mathrm{mg} / \mathrm{Kg}$ b.wt as compared with group II $(P<0.001$ and 0.01$)$. The results acquired in the present study are consistent with the previous investigations where there are decrease in the levels of GPx, CAT, SOD, and XO and increase in MDA level by INHRIF in comparison to the normal, revitalizing the attenuated scavenging capacity of the hepatocytes.

The histopathological studies revealed that there is change in the normal liver architecture and evident hepatocellular necrosis, congestions of sinusoidal spaces in the centrilobular area, steatosis, and inflammation in group II in comparison to group I. Treatment with Silymarin in group III prevented all the histopathological abnormalities induced by INH-RIF which is in agreement with previous findings of Asha et al. [47]. Group III showed maximum recovery of hepatocytes specifying its significant hepatoprotective activity. Similarly group $\mathrm{V}$ also showed marked recovery but recovery was lesser compared to group III and more significant compared 

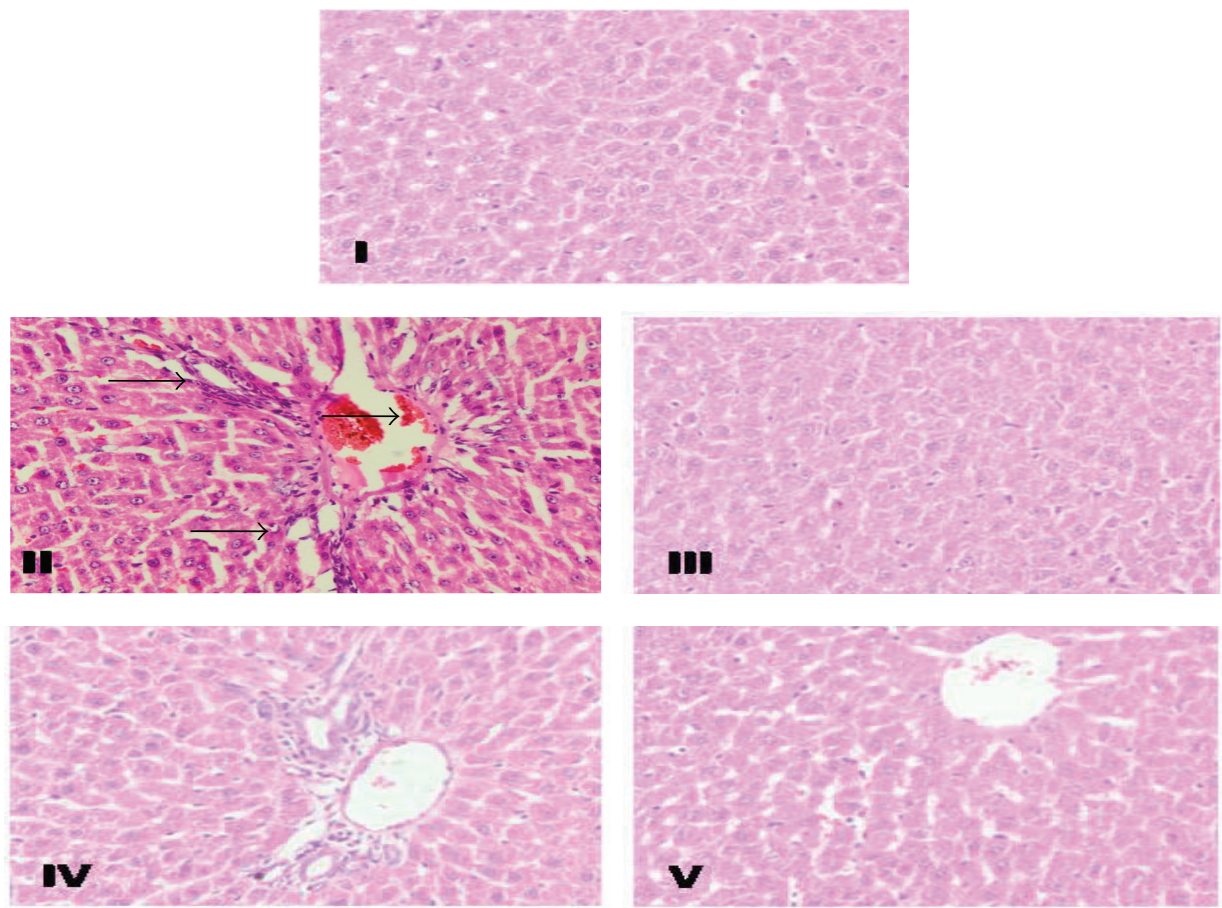

FIGURE 2: Representative photomicrographs showed effects of KPEt on INH-RIF induced histological changes in the rat livers. Representative photomicrographs (magnification $\times 40$ ). Group I: liver sections treated with $0.9 \%$ normal saline showing normal liver architecture. Group II: only INH-RIF induced liver showing portal inflammation, vacuolation, and fatty changes. Group III: liver sections of INH-RIF and Silymarin treated liver showing normal architecture. Group IV: liver sections of INH-RIF and KPEt $200 \mathrm{mg} / \mathrm{kg}$ b.wt treated group showing mild inflammation and steatosis. Group V: liver sections of INH-RIF and KPEt $400 \mathrm{mg} / \mathrm{kg}$ b.wt treated showing almost normal architecture.

to group IV as shown in Figure 2. The hepatic histological changes revealed that the reactive oxygen metabolites and lipid peroxidation could be the reason for different hepatic cellular injuries, that is, centrilobular necrosis, hepatic cell augmentation, steatosis, ballooning degeneration, and periportal fibrosis with impairment of normal liver engineering. The acetylated product of INH, acetylhydrazine, covalently binds to lipid membranes of liver and causes oxidative deterioration of lipids resulting in adipose tissue displacement in the hepatic cells [48]. The photomicrographical investigation of groups III and V shows the recovery of hepatocytes from steatosis, necrosis, and inflammation in comparison to group II.

Conventional immunohistochemistry evaluation of the liver was performed to supplementarily support the biochemical and histopathological examination evidence. The effect of INH-RIF induced NF- $\kappa$ B activation led to maximum nuclear translocation signifying INH-RIF to cause activation of NF- $\kappa \mathrm{B}$. However, KPEt treated groups caused a marked attenuation in nuclear translocation as shown in Figure 3. The activation of NF- $\kappa \mathrm{B}$ linked regulatory pathways generally underlies inflammatory processes, and an increase in the nuclear translocation of NF- $\kappa \mathrm{B}$ has been demonstrated [49]. The transcription factor NF- $\kappa \mathrm{B}$ helps to regulate the expression of several genes activated during inflammation and is implicated in several phenomenon such as cellular proliferation and preclusion of apoptosis [50].
Substantial evidence reveals that the activation of NF$\kappa \mathrm{B}$ upregulates the transcription of COX-2 gene which is responsible for the development of inflammatory response. COX-2 is capable of forming the prostaglandin synthase enzymes, through stimulation of the prostaglandin production pathway [51]. The inhibition of COX-2 has been revealed to exert the hepatoprotective effect in liver damage [52]. Brown color clearly indicates the more number of cells having COX-2 expression (hence more damage) in group II when compared with that of group I. Treatment with Silymarin in group III results in markedly reducing the number of cells showing expression of COX-2. However, there was no marked difference observed in the expression of COX-2 in group IV as compared with group II. Group V showed lesser expression of COX-2 compared to group II. We observed that there is decrease in COX-2 expression by Silymarin and KPEt (group $\mathrm{V}$ only) which indicates inhibition of prostaglandin synthesis and amelioration of the inflammatory reaction Figure 4.

\section{Conclusions}

In the present study, KPEt showed protective effect against INH-RIF induced hepatocellular damage by inhibiting oxidative stress, maintaining balance of antioxidant (enzymatic and nonenzymatic) and distinct decline in COX- 2 and NF- $\kappa \mathrm{B}$ expressions in rodents. The hepatoprotective capacity of KPEt is possibly because of free radical scavenging and antioxidant 

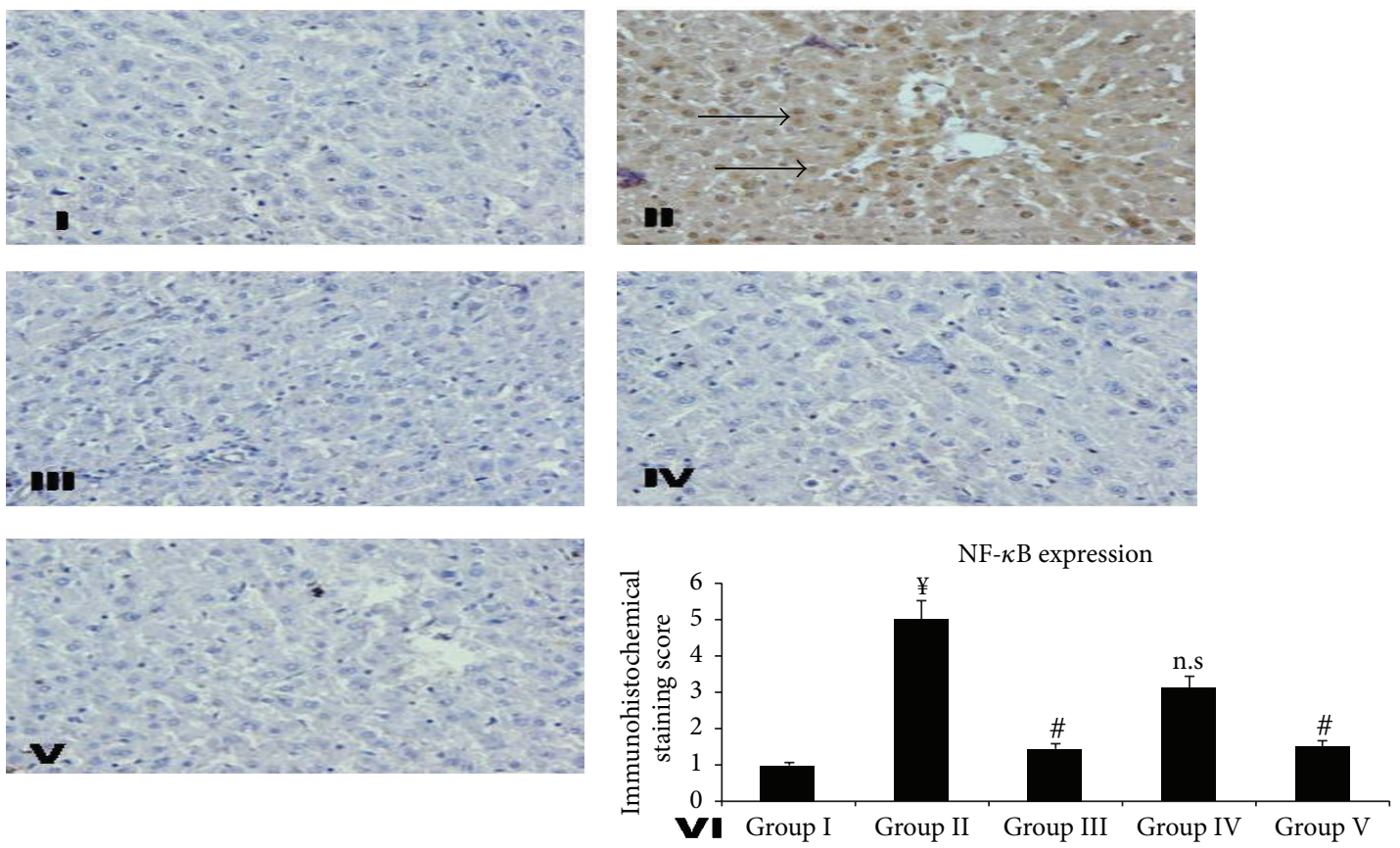

FIgURE 3: Effect of different doses of KPEt on RIF-INH induced NF- $\kappa$ B expression in rat liver. Representative photomicrographs (magnification $\times 40$ ). Group I: liver sections of $0.9 \%$ normal saline treated rats. Group II: hepatic sections of only RIF-INH fed rats showing higher nuclear translocation of NF- $\kappa$ B. Group III: liver sections of RIF-INH and Silymarin treated group showing almost no expressions of nuclear translocation of NF- $\kappa$ B. Group IV: liver sections of RIF-INH and KPEt $200 \mathrm{mg} / \mathrm{kg}$ b.wt treated group showing mild expressions of nuclear translocation of NF- $\kappa$ B. Group V: liver sections of RIF-INH and KPEt $400 \mathrm{mg} / \mathrm{kg}$ b.wt treated group showing less expressions of nuclear translocation of NF- $\kappa$ B. Group VI: scoring data for NF- $\kappa$ B positive cells counted on ten different loci randomly selected on the slide. Values are expressed as ${ }^{\sharp} P<0.001$, toxic versus normal, ${ }^{*} P<0.05$, extract treated groups versus toxic, ${ }^{\#} P<0.01$, extract treated groups versus toxic, and ${ }^{¥} P<0.001$, extract treated groups versus toxic; n.s, not significant.
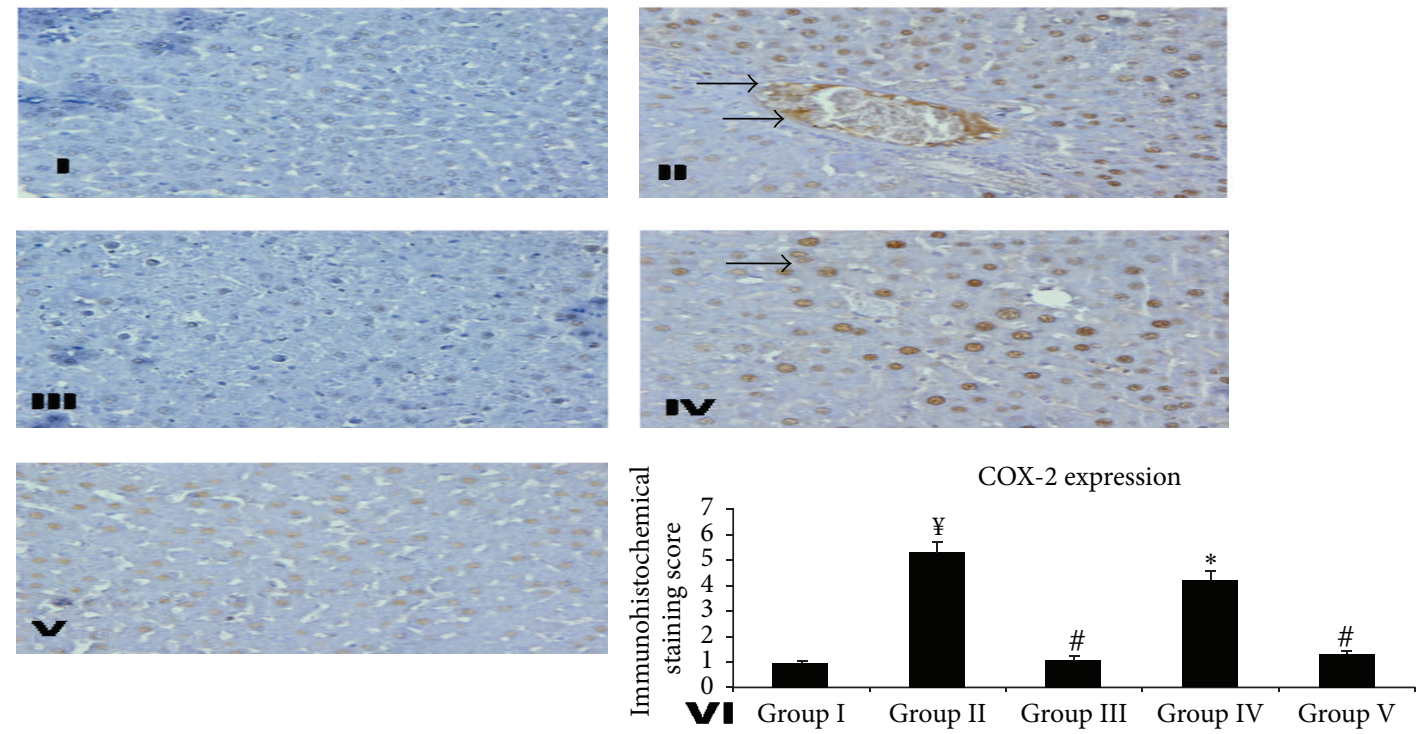

FIGURE 4: Effect of different doses of KPEt on RIF-INH induced COX-2 expression in rat liver. Representative photomicrographs (magnification $\times 40$ ). Group I: liver sections of $0.9 \%$ normal saline treated rats. Group II: hepatic sections of only RIF-INH fed rats showing higher expression of COX-2 as brown patches. Group III: liver sections of RIF-INH and Silymarin treated group showing almost no expressions. Group IV: liver sections of RIF-INH and KPEt $200 \mathrm{mg} / \mathrm{kg}$ b.wt treated group showing moderate expressions. Group V: liver sections of RIF-INH and KPEt $400 \mathrm{mg} / \mathrm{kg}$ b.wt treated group showing mild expressions. Group VI: scoring data for COX-2 positive cells counted on ten different loci randomly selected on the slide. Values are expressed as ${ }^{¥} P<0.001$, toxic versus normal, ${ }^{*} P<0.05$, extract treated groups versus toxic, ${ }^{\#} P<0.01$, extract treated groups versus toxic, and ${ }^{¥} P<0.001$, extract treated groups versus toxic; n.s, not significant. 
property resulting from the presence of flavonoids and phenolic acids in the extract as analyzed by using UHPLCDAD-QToF-MS.

\section{Conflict of Interests}

The authors declare that there is no conflict of interests regarding the publication of this paper.

\section{Acknowledgments}

Mubashir Hussain Masoodi would like to present his gratitude to University Grants Commission (UGC) of India for financial support on this research project F. no 42-861/2013 (SR). The authors are also thankful to the National Center for Natural Product Research (NCNPR), University of Mississippi, USA, for facilitating UHPLC-MS related work.

\section{References}

[1] WHO Reports, Global Tuberculosis Control, 2013.

[2] S. A. Tasduq, P. Kaiser, S. C. Sharma, and R. K. Johri, "Potentiation of isoniazid-induced liver toxicity by rifampicin in a combinational therapy of antitubercular drugs (rifampicin, isoniazid and pyrazinamide) in Wistar rats: a toxicity profile study," Hepatology Research, vol. 37, no. 10, pp. 845-853, 2007.

[3] “Isoniazid," Tuberculosis, vol. 88, no. 2, pp. 112-116, 2008.

[4] “Rifampin,” Tuberculosis, vol. 88, no. 2, pp. 151-154, 2008.

[5] T. C. Sarich, T. Zhou, S. P. Adams, A. I. Bain, R. A. Wall, and J. M. Wright, "A model of isoniazid-induced hepatotoxicity in rabbits," Journal of Pharmacological and Toxicological Methods, vol. 34, no. 2, pp. 109-116, 1995.

[6] B. Zhang, S. Sun, L. Shen et al., "DNA methylation in the rat livers induced by low dosage isoniazid treatment," Environmental Toxicology and Pharmacology, vol. 32, no. 3, pp. 486-490, 2011.

[7] S. Agal, R. Baijal, S. Pramanik et al., "Monitoring and management of antituberculosis drug induced hepatotoxicity," Journal of Gastroenterology and Hepatology, vol. 20, no. 11, pp. 1745$1752,2005$.

[8] R. Khan and S. Sultana, "Farnesol attenuates 1,2-dimethylhydrazine induced oxidative stress, inflammation and apoptotic responses in the colon of Wistar rats," Chemico-Biological Interactions, vol. 192, no. 3, pp. 193-200, 2011.

[9] A. Salatino, C. C. Fernandes-Silva, A. A. Righi, and M. L. F. Salatino, "Propolis research and the chemistry of plant products," Natural Product Reports, vol. 28, no. 5, pp. 925-936, 2011.

[10] M. C. Búfalo, I. Ferreira, G. Costa et al., "Propolis and its constituent caffeic acid suppress LPS-stimulated pro-inflammatory response by blocking NF- $\kappa \mathrm{B}$ and MAPK activation in macrophages," Journal of Ethnopharmacology, vol. 149, no. 1, pp. 8492, 2013.

[11] N. Kalogeropoulos, S. J. Konteles, E. Troullidou, I. Mourtzinos, and V. T. Karathanos, "Chemical composition, antioxidant activity and antimicrobial properties of propolis extracts from Greece and Cyprus," Food Chemistry, vol. 116, no. 2, pp. 452-461, 2009.

[12] V. Lagouri, D. Prasianaki, and F. Krysta, "Antioxidant properties and phenolic composition of greek propolis extracts," International Journal of Food Properties, vol. 17, no. 3, pp. 511-522, 2014.
[13] N. Oršolić and I. Bašić, "Immunomodulation by water-soluble derivative of propolis: a factor of antitumor reactivity," Journal of Ethnopharmacology, vol. 84, no. 2-3, pp. 265-273, 2003.

[14] S. Sobočanec, T. Balog, A. Šari et al., "Antitumor effect of Croatian propolis as a consequence of diverse sex-related dihydropyrimidine dehydrogenase (DPD) protein expression," Phytomedicine, vol. 18, no. 10, pp. 852-858, 2011.

[15] Y. Nakajima, M. Shimazawa, S. Mishima, and H. Hara, "Water extract of propolis and its main constituents, caffeoylquinic acid derivatives, exert neuroprotective effects via antioxidant actions," Life Sciences, vol. 80, no. 4, pp. 370-377, 2007.

[16] M. Bhadauria, S. K. Nirala, and S. Shukla, "Multiple treatment of propolis extract ameliorates carbon tetrachloride induced liver injury in rats," Food and Chemical Toxicology, vol. 46, no. 8, pp. 2703-2712, 2008.

[17] F. Pellati, G. Orlandini, D. Pinetti, and S. Benvenuti, "HPLCDAD and HPLC-ESI-MS/MS methods for metabolite profiling of propolis extracts," Journal of Pharmaceutical and Biomedical Analysis, vol. 55, no. 5, pp. 934-948, 2011.

[18] S. I. Falcão, N. Vale, P. Gomes et al., "Phenolic profiling of Portuguese propolis by LC-MS spectrometry: uncommon propolis rich in flavonoid glycosides," Phytochemical Analysis, vol. 24, no. 4, pp. 309-318, 2013.

[19] E. Sommella, G. Pepe, F. Pagano et al., "UHPLC profiling and effects on LPS-stimulated J774A.1 macrophages of flavonoids from bergamot (Citrus bergamia) juice, an underestimated waste product with high anti-inflammatory potential," Journal of Functional Foods, vol. 7, no. 1, pp. 641-649, 2014.

[20] B. Huang, X. Ban, J. He, J. Tong, J. Tian, and Y. Wang, "Hepatoprotective and antioxidant activity of ethanolic extracts of edible lotus (Nelumbo nucifera Gaertn.) leaves," Food Chemistry, vol. 120, no. 3, pp. 873-878, 2010.

[21] D. C. Garrat, The Quantitative Analysis of Drugs, Chapman \& Hall, Tokyo, Japan, 1983.

[22] C. Beauchamp and I. Fridovich, "Superoxide dismutase: improved assays and an assay applicable to acrylamide gels," Analytical Biochemistry, vol. 44, no. 1, pp. 276-287, 1971.

[23] Organisation for Economic Cooperation and Development, Organization for Economic Cooperation and Development (OECD) Guidelines for Testing of Chemicals, Organisation for Economic Co-Operation and Development (OECD), 2001.

[24] E. I. Saad, S. M. El-Gowilly, M. O. Sherhaa, and A. E. Bistawroos, "Role of oxidative stress and nitric oxide in the protective effects of $\alpha$-lipoic acid and aminoguanidine against isoniazidrifampicin-induced hepatotoxicity in rats," Food and Chemical Toxicology, vol. 48, no. 7, pp. 1869-1875, 2010.

[25] M. U. Rehman, N. Ali, S. Rashid et al., "Alleviation of hepatic injury by chrysin in cisplatin administered rats: probable role of oxidative and inflammatory markers," Pharmacological Reports, vol. 66, no. 6, pp. 1050-1059, 2014.

[26] M. Tahir, M. U. Rehman, A. Lateef et al., "Diosmin protects against ethanol-induced hepatic injury via alleviation of inflammation and regulation of TNF- $\alpha$ and NF- $\kappa$ B activation," Alcohol, vol. 47, no. 2, pp. 131-139, 2013.

[27] A. S. El Senousy, M. A. Farag, D. A. Al-Mahdy, and L. A. Wessjohann, "Developmental changes in leaf phenolics composition from three artichoke cvs. (Cynara scolymus) as determined via UHPLC-MS and chemometrics," Phytochemistry, vol. 108, pp. 67-76, 2014. 
[28] G. M. Sulaiman, K. W. A. Sammarrae, A. H. Ad'hiah et al., "Chemical characterization of iraqi propolis samples and assessing their antioxidant potentials," Food and Chemical Toxicology, vol. 49, no. 9, pp. 2415-2421, 2011.

[29] I. Q. Gulala, S. A. Roshna, A. A. Zheen, F. A. Zana, and A. H. Saad, "Protective effects of quercetin against isoniazid and rifampicin induced hepatotoxicity in rats," American Journal of Plant Sciences, vol. 2, no. 3, pp. 56-60, 2014.

[30] G. Pushpavalli, P. Kalaiarasi, C. Veeramani, and K. V. Pugalendi, "Effect of chrysin on hepatoprotective and antioxidant status in D-galactosamine-induced hepatitis in rats," European Journal of Pharmacology, vol. 631, no. 1-3, pp. 36-41, 2010.

[31] C. E. Costentin, F. Roudot-Thoraval, E.-S. Zafrani et al., "Association of caffeine intake and histological features of chronic hepatitis C," Journal of Hepatology, vol. 54, no. 6, pp. 1123-1129, 2011.

[32] X. Han, T. Shen, and H. Lou, "Dietary polyphenols and their biological significance," International Journal of Molecular Sciences, vol. 8, no. 9, pp. 950-988, 2007.

[33] D. Procházková, I. Boušová, and N. Wilhelmová, "Antioxidant and prooxidant properties of flavonoids," Fitoterapia, vol. 82, no. 4, pp. 513-523, 2011.

[34] A. René, M.-L. Abasq, D. Hauchard, and P. Hapiot, "How do phenolic compounds react toward superoxide ion? A simple electrochemical method for evaluating antioxidant capacity," Analytical Chemistry, vol. 82, no. 20, pp. 8703-8710, 2010.

[35] L. M. Magalhães, M. A. Segundo, S. Reis, and J. L. F. C. Lima, "Methodological aspects about in vitro evaluation of antioxidant properties," Analytica Chimica Acta, vol. 613, no. 1, pp. 1-19, 2008.

[36] G.-C. Yen and P.-D. Duh, "Scavenging effect of methanolic extracts of peanut hulls on free-radical and active-oxygen species," Journal of Agricultural and Food Chemistry, vol. 42, no. 3, pp. 629-632, 1994.

[37] T. Münzel, T. Heitzer, and D. G. Harrison, "The physiology and pathophysiology of the nitric oxide/superoxide system," Herz, vol. 22, no. 3, pp. 158-172, 1997.

[38] S. C. Pradhan and C. Girish, "Hepatoprotective herbal drug, silymarin from experimental pharmacology to clinical medicine," Indian Journal of Medical Research, vol. 124, pp. 491-504, 2006.

[39] L. Tůmová, J. Tůma, K. Megušar, and M. Doležal, "Substituted pyrazinecarboxamides as abiotic elicitors of flavolignan production in Silybum marianum (L.) gaertn cultures in vitro," Molecules, vol. 15, no. 1, pp. 331-340, 2010.

[40] J. Wills and V. V. Asha, "Preventive and curative effect of Lygodium flexuosum (L.) Sw. on carbon tetrachloride induced hepatic fibrosis in rats," Journal of Ethnopharmacology, vol. 107, no. 1, pp. 7-11, 2006.

[41] S. A. Tasduq, K. Peerzada, S. Koul, R. Bhat, and R. K. Johri, "Biochemical manifestations of anti-tuberculosis drugs induced hepatotoxicity and the effect of silymarin," Hepatology Research, vol. 31, no. 3, pp. 132-135, 2005.

[42] T. Lynch and A. Price, "The effect of cytochrome $\mathrm{P}_{450}$ metabolism on drug response, interactions, and adverse effects," American Family Physician, vol. 76, no. 3, pp. 391-396, 2007.

[43] D. K. Ingawale, S. K. Mandlik, and S. R. Naik, "Models of hepatotoxicity and the underlying cellular, biochemical and immunological mechanism(s): a critical discussion," Environmental Toxicology and Pharmacology, vol. 37, no. 1, pp. 118-133, 2014.
[44] Y.-S. Huang, H.-D. Chern, W.-J. Su et al., "Cytochrome P450 2E1 genotype and the susceptibility to antituberculosis druginduced hepatitis," Hepatology, vol. 37, no. 4, pp. 924-930, 2003.

[45] C. Pauli-Magnus and P. J. Meier, "Hepatobiliary transporters and drug-induced cholestasis," Hepatology, vol. 44, no. 4, pp. 778-787, 2006.

[46] P. Muriel, "Role of free radicals in liver diseases," Hepatology International, vol. 3, no. 4, pp. 526-536, 2009.

[47] T. N. K. Asha, L. L. Ramesh, B. N. Hanumantappa, and C. B. K. Sanjeev, "Cytotoxicity and hepatoprotective attributes of methanolic extract of Rumex vesicarius L.," Biological Research, vol. 48, no. 1, article 19, 2015.

[48] G. G. Graham, K. F. Scott, and R. O. Day, "Alcohol and paracetamol," Australian Prescriber, vol. 27, no. 1, pp. 14-15, 2004.

[49] C. Morais, G. Gobe, D. W. Johnson, and H. Healy, "The emerging role of nuclear factor kappa B in renal cell carcinoma," International Journal of Biochemistry and Cell Biology, vol. 43, no. 11, pp. 1537-1549, 2011.

[50] M. Brown, J. Cohen, P. Arun, Z. Chen, and C. Van Waes, "NFkappaB in carcinoma therapy and prevention," Expert Opinion on Therapeutic Targets, vol. 12, no. 9, pp. 1109-1122, 2008.

[51] R. N. DuBois, S. B. Abramson, L. Crofford et al., "Cyclooxygenase in biology and disease," FASEB Journal, vol. 12, no. 12, pp. 1063-1073, 1998.

[52] B. B. Vadiraja, N. W. Gaikwad, and K. M. Madyastha, "Hepatoprotective effect of C-phycocyanin: protection for carbon tetrachloride and $R-(+)$-pulegone-mediated hepatotoxicty in rats," Biochemical and Biophysical Research Communications, vol. 249, no. 2, pp. 428-431, 1998. 


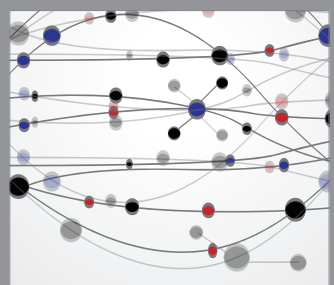

The Scientific World Journal
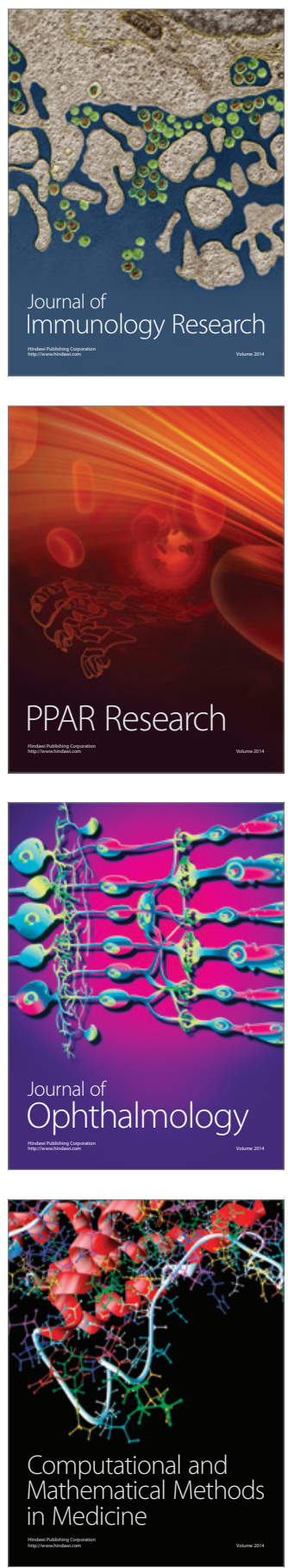

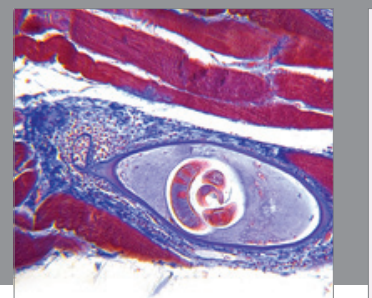

Gastroenterology

Research and Practice
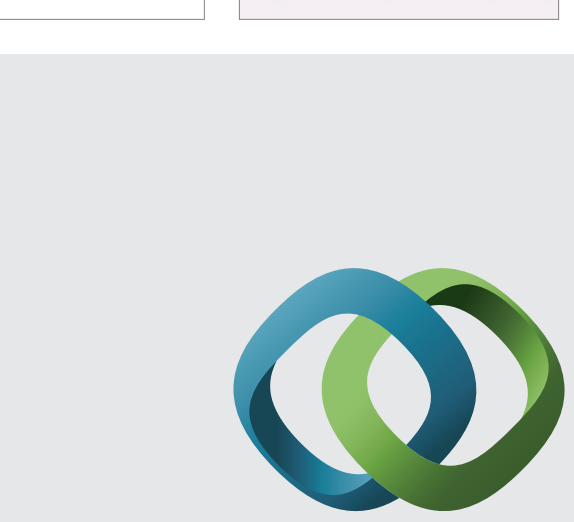

\section{Hindawi}

Submit your manuscripts at

http://www.hindawi.com
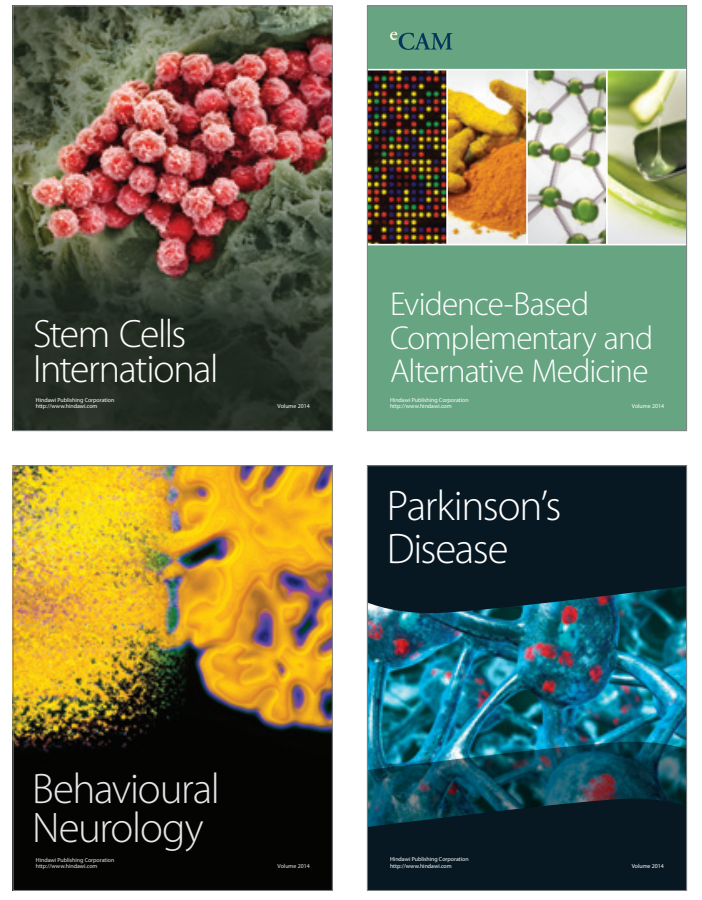
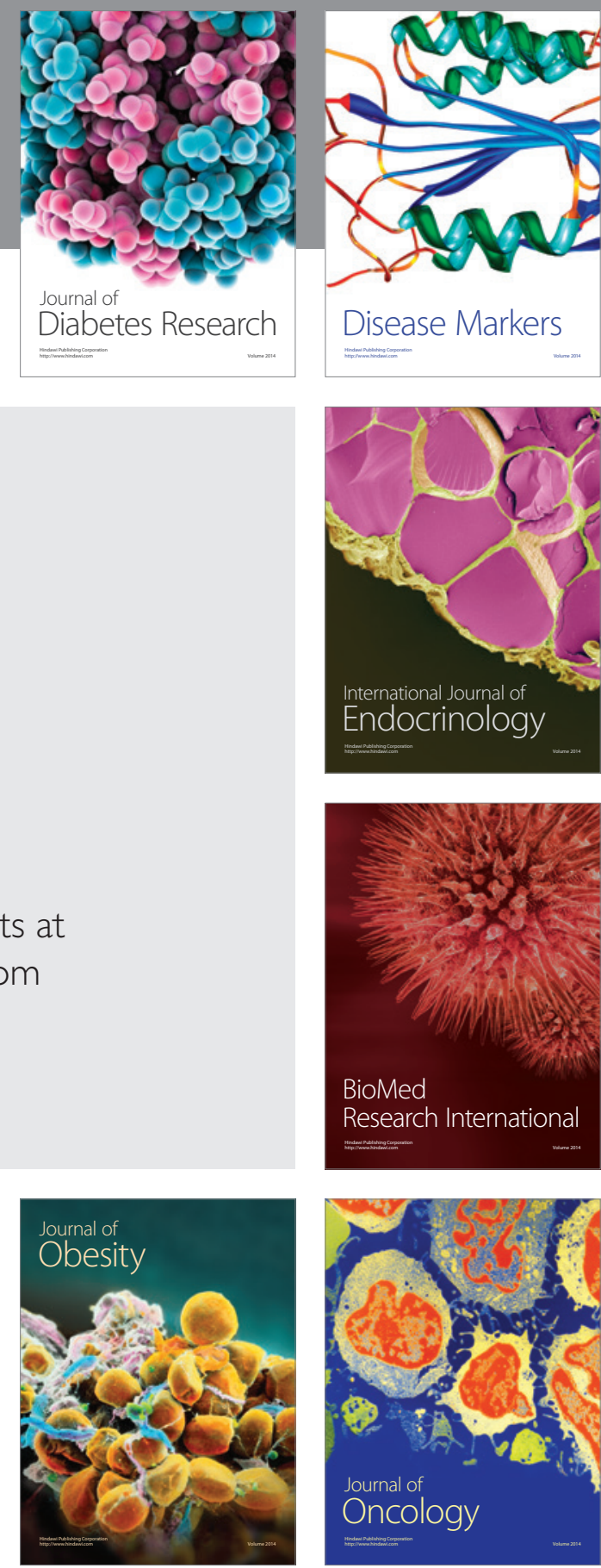

Disease Markers
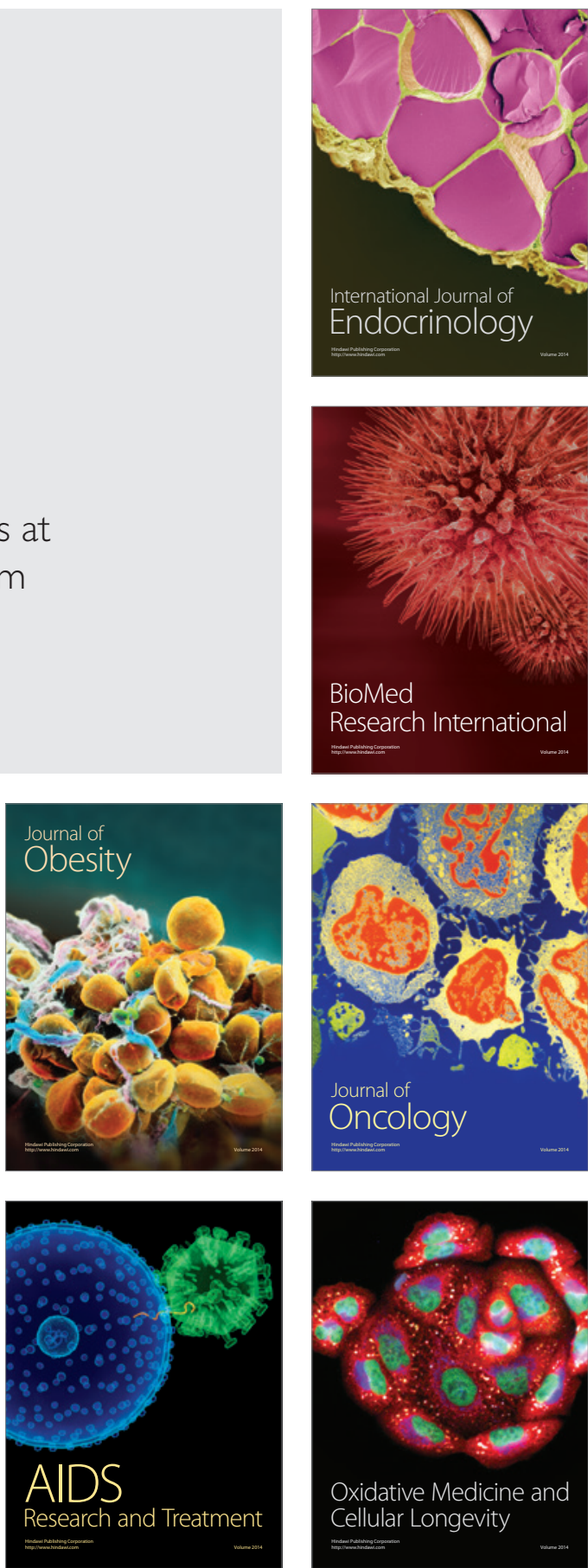